\title{
Effects of Curcumin Combined With the 5-alpha Reductase Inhibitor Dutasteride on LNCaP Prostate Cancer Cells
}

\author{
AKINORI NAKAYAMA ${ }^{1}$, HISAMITSU IDE $^{1}$, YAN LU $^{2}$, AYANO TAKEI $^{3}$, KAZUNORI FUKUDA $^{3}$, \\ AKIYOSHI OSAKA ${ }^{1}$, GAKU ARAI ${ }^{1}$, SHIGEO HORIE ${ }^{2}$, HIROSHI OKADA $^{1}$ and KAZUTAKA SAITO ${ }^{1}$ \\ ${ }^{1}$ Department of Urology, Dokkyo Medical University Saitama Medical Center, Saitama, Japan; \\ ${ }^{2}$ Department of Urology, Juntendo University, Graduate School of Medicine, Tokyo, Japan; \\ ${ }^{3}$ Collaborative Research Center, Dokkyo Medical University Saitama Medical Center, Saitama, Japan
}

\begin{abstract}
Background/Aim: Curcumin is a natural compound of turmeric, which inhibits prostate cancer cell proliferation. This study examined whether treatment of LNCaP prostate cancer cells with the combination of curcumin and dutasteride, a 5-alpha reductase inhibitor, affect proliferation and the amount of testosterone and dihydrotestosterone. Materials and Methods: LNCaP Cells were incubated with curcumin or the combination of curcumin and dutasteride and cell proliferation was measured at 72 h. LC-MS/MS was used to determine testosterone and dihydrotestosterone concentrations in prostate cancer cells. Results: Curcumin combined with dutasteride suppressed proliferation and affected apoptosis of LNCaP cells. The combination of curcumin and dutasteride also reduced the amount of testosterone and dihydrotestosterone in LNCaP cells. The secretion of prostate-specific antigen was inhibited by the combination treatment in a dose-dependent manner. Conclusion: Treatment with the combination of curcumin and dutasteride may interfere with the intra-tumoral androgen activity.
\end{abstract}

Androgen signaling plays a key role in the propagation and differentiation of prostate gland cells and also in prostate carcinogenesis (1). The 5-alpha reductase inhibitor dutasteride inhibits conversion of testosterone to dihydrotestosterone. Dutasteride is used to treat benign prostatic hyperplasia $(\mathrm{BPH})$ as it shrinks the prostate and reduces the levels of prostate-specific antigen (PSA) by at least $40 \%$ (2). Relative to testosterone, dihydrotestosterone has considerably more

This article is freely accessible online.

Correspondence to: Hisamitsu Ide, MD, Ph.D., Department of Urology, Dokkyo Medical University Saitama Medical Center, 2-150, Minamikoshigaya, Koshigaya, Saitama, 343-8555 Japan. Tel: +81 48965111, Fax: +81 489658927, e-mail: ihisamit@ dokkyomed.ac.jp

Key Words: Curcumin, dutasteride, testosterone, prostate cancer. potent biological activities in various tissues (3). The Reduction by Dutasteride of Prostate Cancer Events (REDUCE) trial is a randomized controlled trial, which tests dutasteride for prostate cancer chemoprevention over a 4-year period in patients between 50 to 75 years of age who had prostate-specific antigen (PSA) levels of 2.5 to $10.0 \mathrm{ng}$ per milliliter (4). Risk of prostate cancer was reduced by approximately $25 \%$ in randomized trials using dutasteride (4, $5)$; therefore, inhibiting the conversion of testosterone into dihydrotestosterone might reduce the risk of prostate cancer.

Curcumin, a spice often used as an ingredient in curry and other dishes, is an active ingredient comprising about $5 \%$ of turmeric. Previously, we have reported that curcumin can affect steroidogenesis in prostate cancer. The study indicated that curcumin significantly reduced testosterone levels in LNCaP cells through AKR1C2 expression, and thereby, suppressed the proliferation of LNCaP and 22Rv1 prostate cancer cells, which expressed the androgen receptor (6). In addition, the suppression of nuclear factor- $\mathrm{kB}(\mathrm{NF}-\mathrm{kB})$ and activator protein-1 (AP-1) has validated that curcumin has powerful anti-oxidative and anti-inflammatory functions (7) and triggers apoptosis through DNA damage, thus impeding the progression of various cancers (8).

As both dutasteride and curcumin have suppressive effects on intratumoral androgen production, the current study examined whether dutasteride and curcumin had an additive inhibitory effect on cell proliferation and PSA production. The experimental results showed that curcumin and dutasteride have an inhibitory effect on the malignant progression of prostate cancer, supporting the clinical potential of this combination for the prevention and therapy of prostate cancer.

\section{Materials and Methods}

Human prostate cancer cell line and cell culture. The human prostate cancer cell line $\mathrm{LNCaP}$ was obtained from the American Type Culture Collection (ATCC, Manassas, VA, USA). The cells were cultured in 10-cm diameter dishes with RPMI 1640 Medium (Gibco, Gran Island, NY, USA) containing 10\% (v/v) fetal bovine 

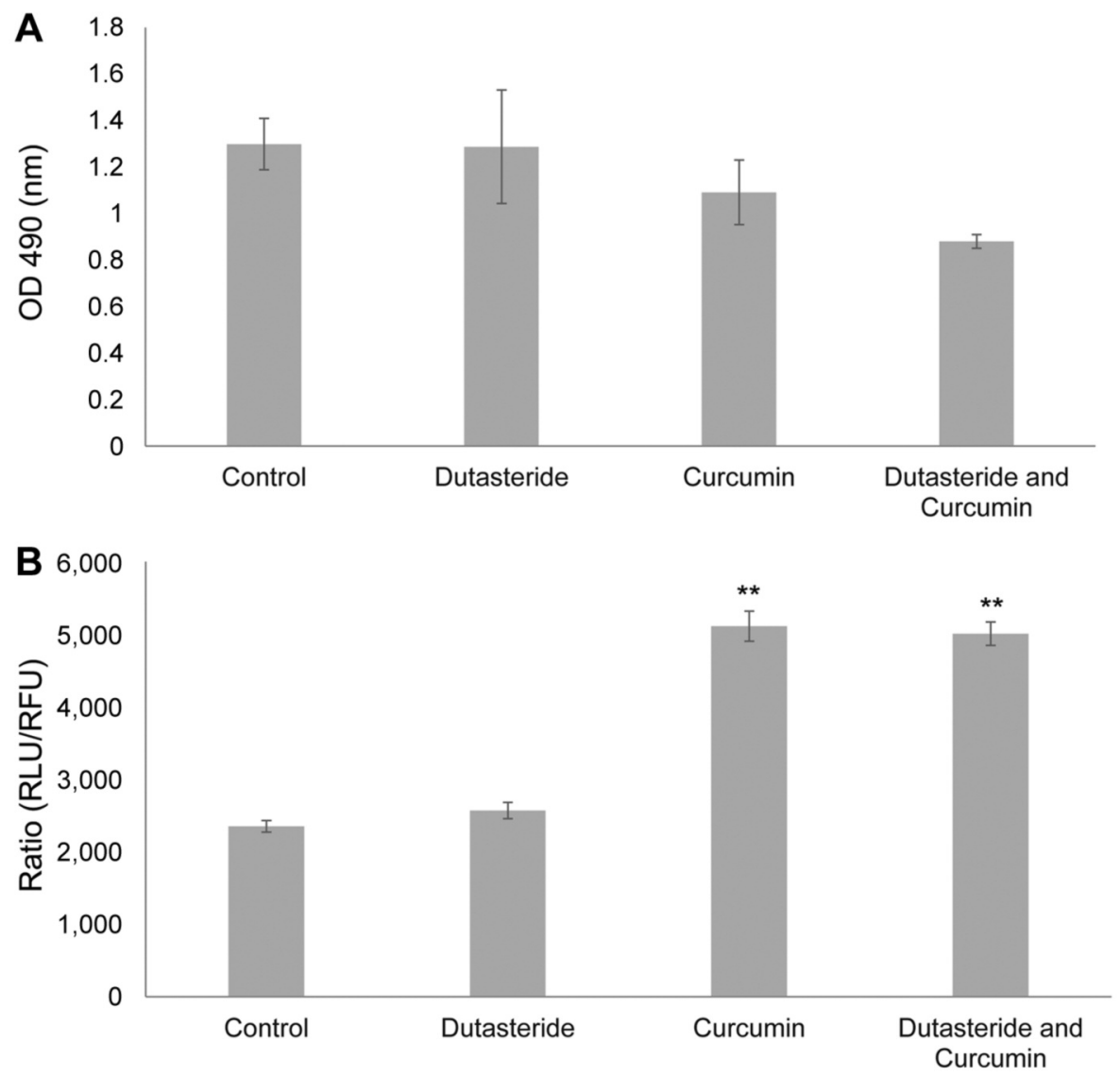

Figure 1. Effects of curcumin and dutasteride on LNCaP cell growth. A) Cells were treated with $10 \mu M$ curcumin or/and $10 \mu M$ dutasteride, and MTS proliferation assays were performed. Each point represents the mean \pm SEM of six wells. The combination of curcumin and dutasteride has an inhibitory effect on the viability of LNCaP cells, although no statistical significance was observed ( $p=0.087)$ compared with the control $(0 \mu M)$. B) Induction and quantification of apoptosis were examined following treatment of curcumin and dutasteride. LNCaP cells were incubated with 25 $\mu M$ curcumin alone and with $10 \mu M$ dutasteride for 6 h. The error bar represents SEM from 6 wells. The vertical axis shows the ratio of caspase3/7 activity [relative luminescence units $(R L U)$ ] to viable cells [relative fluorescence units $(R F U)$ ]. A statistical significance $(* * p<0.01)$ is indicated compared with the control $(0 \mu \mathrm{M})$.

serum (Gibco) and $1 \%$ penicillin-streptomycin (Gibco) at $37^{\circ} \mathrm{C}$ under $5 \% \mathrm{CO}_{2}$, and passaged with TrypLE Select (Gibco) every three days to maintain a cell monolayer. To determine testosterone and dihydrotestosterone levels in LNCaP cells, charcoal strippedFBS (Gibco) was used in the medium instead of FBS for $24 \mathrm{~h}$ before curcumin treatment. $\mathrm{LNCaP}$ cells were characterized for androgen receptor expression.

An effective preparation of curcumin (THERACURMIN) (9), a nano-particle colloidal dispersion with improved oral bioavailability (THERACURMIN, Theravalues Corp., Tokyo, Japan), was obtained. Curcumin was dissolved in DMSO at a concentration of $10 \mathrm{mM}$ and stored at $-20^{\circ} \mathrm{C}$ until use. $10 \mu \mathrm{M}$ dutasteride (Cayman Chemical Company, Ann Arbor, MI, USA) was used in this study.

Cell proliferation assay. LNCaP cells were incubated with $10 \mu \mathrm{M}$ curcumin with or without $10 \mu \mathrm{M}$ dutasteride. Cell proliferation was then measured by an MTS assay (Promega Corp., Madison, WI, USA) at $72 \mathrm{~h}$. Quintuplet assay repeats were conducted for all treatments, and the results are presented as the mean of three separate experiments.
Apoptosis assay of viability and caspase activation. To determine apoptosis induced by curcumin with or without dutasteride, we measured caspase-3/7 activity using the ApoLive-Glo Multiplex assay (Promega, Corp.). LNCaP cells were plated in a 96-well plate at a density of $1 \times 10^{5}$ cells $/ \mathrm{ml}$ and incubated at $37^{\circ} \mathrm{C}$ overnight. The cells were then incubated with $25 \mu \mathrm{M}$ curcumin with or without $10 \mu \mathrm{M}$ dutasteride for $6 \mathrm{~h}$. In accordance with the manufacturer's protocol, after incubation, $20 \mu \mathrm{l}$ of viability reagent were added to each well and the cells were incubated again for $30 \mathrm{~min}$ at $37^{\circ} \mathrm{C}$. Fluorescence (RFU: relative fluorescence units) was measured at a $400_{\mathrm{EX}} / 505_{\mathrm{EM}}$ wavelength for viability employing a fluorescence spectrophotometer F-7000 (Hitachi, Tokyo, Japan). Finally, we added $100 \mu$ of CaspaseGlo 3/7 Reagent to each well and incubated the cells for $1 \mathrm{~h}$ at room temperature. Luminescence (RLU: relative luminescence units) was measured using the luminometer AB-2350 (Atto, Tokyo, Japan) to detect apoptosis.

Immunoblotting analysis. Subconfluent LNCaP cells were treated with different concentrations of curcumin with or without $10 \mu \mathrm{M}$ 
dutasteride for $24 \mathrm{~h}$. The cells were washed twice with cold PBS and then lysed in RIPA buffer on ice for $10 \mathrm{~min}$. Supernatants were collected following centrifugation of cell lysates at $15,000 \mathrm{~g}$ for 10 $\min$ at $4^{\circ} \mathrm{C}$. Protein concentrations were measured using a Pierce BCA Protein Assay Kit (Thermo Fisher Scientific, Inc., Rockford, IL, USA). Proteins were separated by SDS-PAGE (5-20\%, SuperSep Ace, Wako, Tokyo, Japan) and transferred to a PVDF membrane (Millipore Corporation, Billerica, MA, USA). The membrane was blocked in $1 \%$ BSA (bovine serum albumin) in TBS (Tris-buffered saline) (Blocker: Thermo Fisher Scientific, Inc.) for $1 \mathrm{~h}$ at room temperature and then incubated with i) p-ATM (Abcam, Cambridge, UK, clone\#EP1890Y; 1:1,000 dilution) rabbit monoclonal (phospho S1981), ii) gammaH2AX (Cell Signaling, Beverly, MA, USA; 1:1,000 dilution) rabbit polyclonal antibody, iii) cleaved PARP (Cell Signaling; 1:1,000 dilution) rabbit polyclonal antibody, iv) androgen receptor (Santacruz, Dallas, TX, USA, 1:1,000 dilution) rabbit polyclonal antibody, v) AKR1C2 (ABGENT, WuXi, China; 1:1,000 dilution) rabbit polyclonal antibody, vi) Cytochrome P450(17 $\alpha$ ) (CYP17A1) (Santa Cruz, clone\#D-12; 1:1,000 dilution) rabbit monoclonal antibody, vii) steroid $5 \alpha$-reductase type 1 (SRD5A1) (Proteintec, WuHan, China; 1:1,000 dilution), and viii) steroid 5 $\alpha$-reductase type 2 (SRD5A2) (Abcam, clone\#EPR6181(B); 1:1,000 dilution) rabbit monoclonal antibody overnight at $4^{\circ} \mathrm{C}$. $\beta$-actin antibody (Sigma-Andrich Co., St. Louis, MO, USA. Clone\#AC-15; 1:10,000 dilution) was used as an internal loading control. Blots were washed three times (15 min each) with TBST (Tris-buffered saline containing $0.1 \%$ Tween-20). The blots were then incubated with HRP-conjugated secondary antibody (BioRad Laboratories, Hercules, CA, USA) at a dilution of 1:3,000 for 1 $\mathrm{h}$ at room temperature and washed three times $(15 \mathrm{~min}$ each) with TBST. Proteins were visualized with ECL Western Blotting Detection Reagents (GE Healthcare, Little Chalfont Buckinghamshire, UK) and LAS-3000 mini detection system (Fujifilm Medical Systems, Tokyo, Japan). An image processing program (ImageJ, NIH, Bethesda, MD, USA) was used to quantify the band density.

Mass-spectrometric assay of testosterone and dihydrotestosterone. A brief description of modified procedures is presented here; detailed description can be found in $(10,11)$. Cultured LNCaP cells were suspended in $1 \mathrm{ml}$ of distilled water and homogenized by Ultra-Turrax homogenizer to extract steroids. The concentration of testosterone and dihydrotestosterone was determined using an LCMS/MS system consisting of an Agilent 1290 Infinity LC systems (Agilent technologies, Santa Clara, CA, USA) and an API-5000 triple stage quadrupole mass spectrometer (Applied Biosystems, Chicago, IL, USA). MS analysis was conducted with electro spray ionization (ESI) in the positive-ion mode. The LC-MS/MS system was operated in the multiple reaction monitoring mode to monitor the $\mathrm{m} / \mathrm{z}$ transition, from 394 to 253 for Testosterone-picolinoyl, and from 396 to 203 for dihydrotestosterone-picolinoyl (10). The limits of quantification were $1 \mathrm{pg}$ for testosterone and dihydrotestosterone.

PSA measurement in conditioned medium. LNCaP cells were cultured in growth medium for $24 \mathrm{~h}$ and then treated with curcumin, dutasteride, or their combination. After a 72-h treatment, the conditioned media were collected, centrifuged to remove residual cells, and stored at $-20^{\circ} \mathrm{C}$. The quantitative analysis of the amount of PSA secreted by LNCaP cells was conducted by an immunoassay procedure using a Human (free PSA) ELISA kit (Abcam). An MTS assay was performed at the same time, and results were used for normalization of PSA levels.

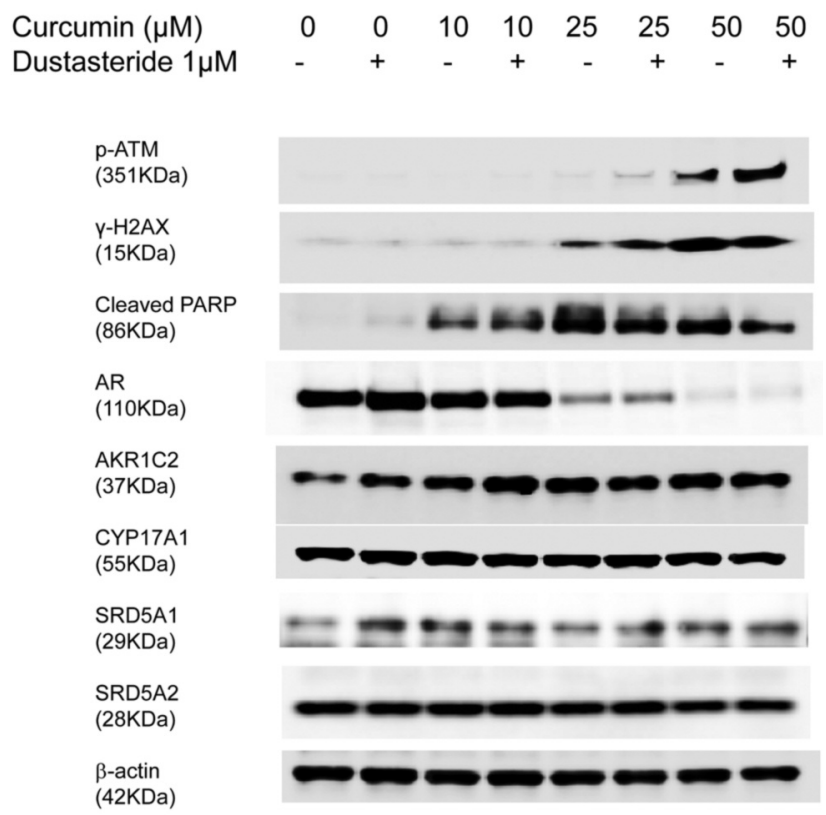

Figure 2. Activation of DNA damage response and the expression of enzymes involved in testosterone metabolism following treatment with curcumin, dutasteride or their combination. Immunoblotting conducted after a 48-hour treatment resulted in the detection of protein expression. The protein bands from top to bottom show phosphorylation of ataxiatelangiectasia-mutated kinase (ATM), phosphorylation of H2AX ( $g$ $H 2 A X)$, poly (ADP-ribose) polymerase (PARP) cleavage androgen receptor (AR), Aldo-Keto reductase 1C2 (AKR1C2), Cytochrome

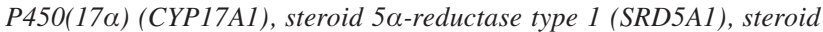
$5 \alpha$-reductase type 2 (SRD5A2) and $\beta$-actin. The internal control used in this study was a mouse anti-human $\beta$-actin antibody.

Statistical analysis. Data are expressed as mean \pm SEM. For statistical analysis, one-way ANOVA tests were used (SPSS). $* p<0.05$ and $* * p<0.01$ were considered statistically significant.

\section{Results}

Curcumin and dutasteride inhibited the growth of LNCaP cells. The effects of curcumin, dutasteride and their combination on cell proliferation were determined by performing an MTS assay on LNCaP cells which express the androgen receptor at various concentrations. The combination of curcumin and dutasteride had an inhibitory effect on the growth of the cells. Viability of LNCaP cells decreased by $16 \%$, as shown in Figure $1 \mathrm{~A}$, when $10 \mu \mathrm{M}$ of curcumin was added to the culture medium. LNCaP cell growth was not suppressed by the use of dutasteride alone. Although not statistically significant, cell growth was inhibited by $33 \%(p=0.087)$ with the combination treatment of $10 \mu \mathrm{M}$ curcumin and $10 \mu \mathrm{M}$ dutasteride.

Curcumin and dutasteride treatment induced apoptosis. Caspase-3/7 activity was assayed to determine apoptosis and the ApoLive-Glo Multiplex Assay was used for quantifying 


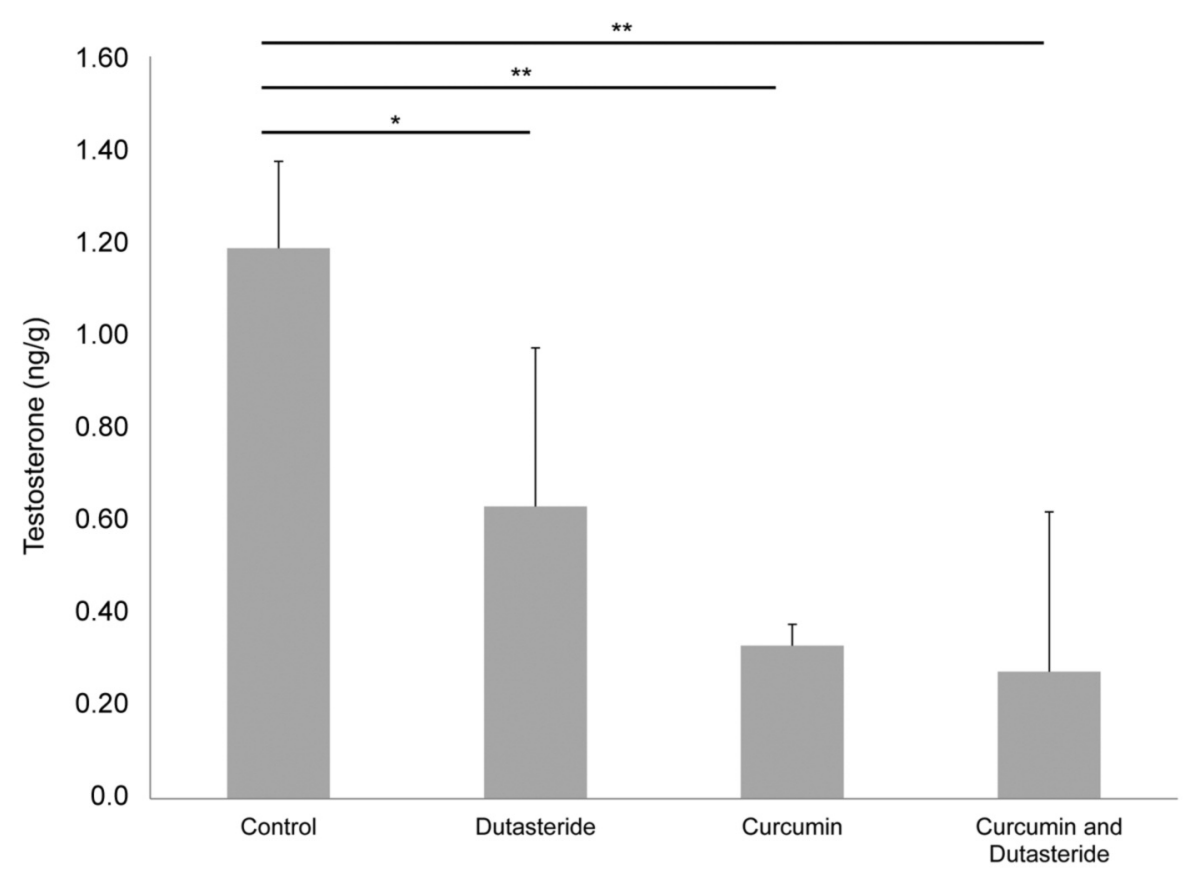

Figure 3. Testosterone levels in LNCaP cells after curcumin and dutasteride treatment. A statistically significant effect is shown following treatment with curcumin $(10,50 \mu \mathrm{M})$ and curcumin with dutasteride $(10 \mu \mathrm{M})$ in comparison with the control $(* p<0.05, * * p<0.01)$.

apoptosis and the ration of caspase-3/7 activity (RLU) to viable cells was determined as described in Materials and Methods. Treatment with $25 \mu \mathrm{M}$ curcumin resulted in a significant increase in the ratio of caspase-3/7 activity (RLU) to viable cells (RLU), as shown in Figure 1B, demonstrating that curcumin-induced apoptosis $(p<0.01)$. Dutasteride alone did not induce apoptosis of LNCaP cells. It is also shown that the combination of $25 \mu \mathrm{M}$ curcumin and $10 \mu \mathrm{M}$ dutasteride induced apoptosis compared to the control $(p<0.01)$, but no additional effect was observed.

Curcumin and dutasteride triggered DNA damage response and PARP cleavage. To determine how curcumin and dutasteride suppress cell proliferation and induce apoptosis, we examined the phosphorylation of ATM and histone H2AX as well as the occurrence of poly (ADP-ribose) polymerase (PARP) cleavage, a marker of apoptosis, by immunoblotting. In addition, to evaluate the effect of curcumin with and without dutasteride on steroidogenesis-related proteins in LNCaP prostate cancer cells (Figure 2), we examined the expression of androgen receptor, AKR1C2, CYP17A1, SRD5A1 and SRD5A2 using western immunoblotting. LNCaP cells were treated with 10 to $50 \mu \mathrm{M}$ curcumin, $1 \mu \mathrm{M}$ dutasteride, and their combination, for $24 \mathrm{~h}$ each.

At the concentrations of $25 \mu \mathrm{M}$ and $50 \mu \mathrm{M}$, curcumin inhibited the expression of androgen receptors and induced phosphorylation of ATM and histone H2AX in LNCaP cells.
Moreover, a combination of curcumin and dutasteride, compared to curcumin alone, induced higher levels of ATM and histone $\mathrm{H} 2 \mathrm{AX}$ phosphorylation.

The expression of AKR1C2, CYP17A1, SRD5A1 and SRD5A2, which are involved in dihydrotestosterone production, was examined to determine changes in testosterone metabolism in prostate cancer cells treated with curcumin and/or dutasteride. Expression of these proteins was not affected by treatment with curcumin and/or dutasteride, with the exception of AKR1C2. The results showed a dose-dependent increase in AKR1C2 expression in LNCaP cells treated with curcumin $(10 \mu \mathrm{M}$ to $50 \mu \mathrm{M})$ and 1 $\mu \mathrm{M}$ dutasteride (Figure 2). The combination of curcumin and dutasteride induced higher levels of AKR1C2 expression compared to treatment with curcumin alone. We obtained similar results using 22Rv1 cells, another androgen receptorpositive prostate cancer cell line.

Treatment with curcumin and dutasteride decreased the levels of testosterone and dihydrotestosterone in LNCaP cells. The levels of testosterone and dihydrotestosterone in $\mathrm{LNCaP}$ decreased after $24 \mathrm{~h}$ treatment with $10 \mu \mathrm{M}$ and $50 \mu \mathrm{M}$ curcumin, respectively. Testosterone levels were reduced from $1.19 \mathrm{ng} / \mathrm{g}$ (control without curcumin) to $0.63 \mathrm{ng} / \mathrm{g}(10 \mu \mathrm{M}$ dutasteride), $0.33 \mathrm{ng} / \mathrm{g}$ (50 $\mu \mathrm{M}$ curcumin) and $0.27 \mathrm{ng} / \mathrm{g}(50$ $\mu \mathrm{M}$ curcumin and $10 \mu \mathrm{M}$ dutasteride) (Figure 3). A considerable decrease was also observed in dihydrotestosterone levels, from $0.34 \mathrm{ng} / \mathrm{g}$ (control) to $0.04 \mathrm{ng} / \mathrm{g}(10 \mu \mathrm{M}$ 


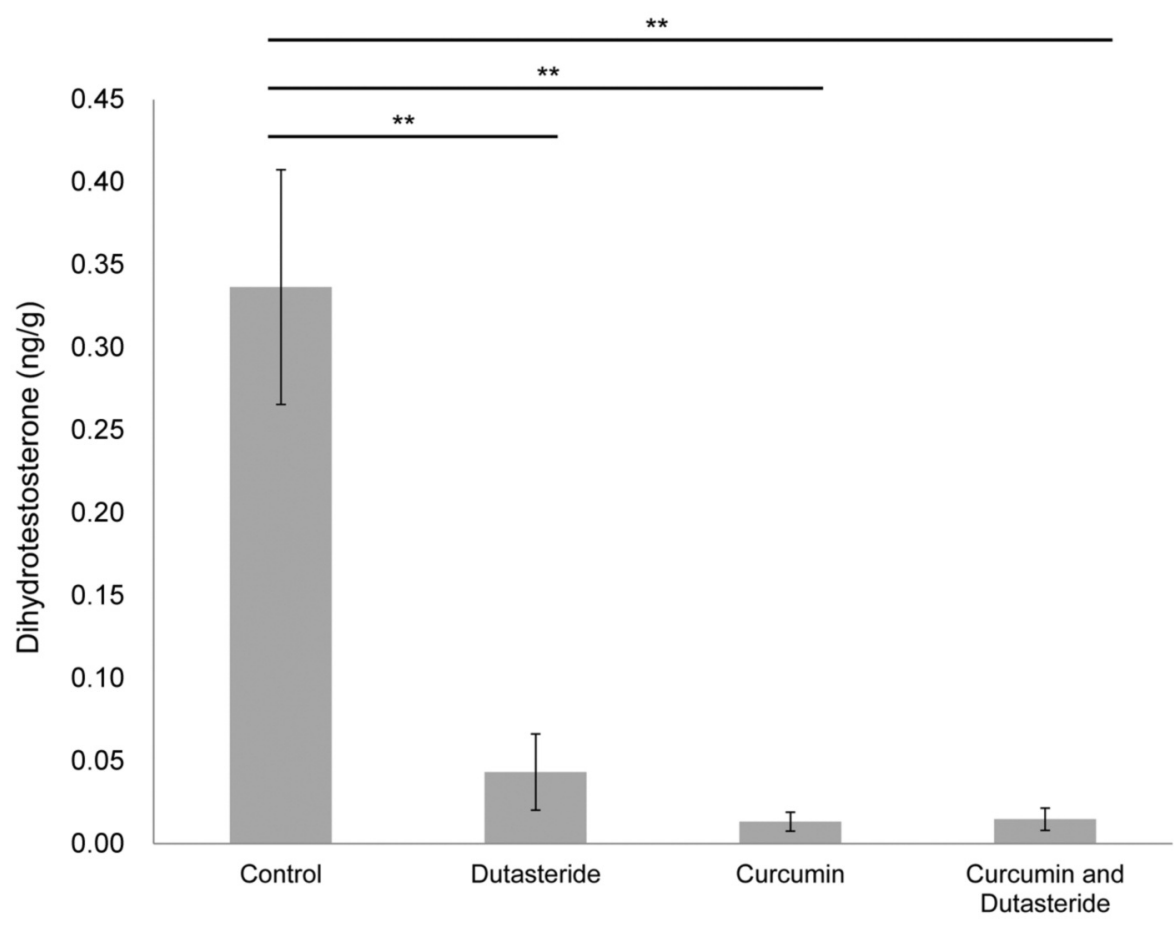

Figure 4. Dihydrotestosterone levels in LNCaP cells after curcumin and dutasteride treatment. A statistically significant effect is shown following treatment with curcumin $(10,50 \mu \mathrm{M})$ and curcumin with dutasteride $(10 \mu \mathrm{M})$ compared with the control $(* * p<0.01)$.

dutasteride), $0.01 \mathrm{ng} / \mathrm{g}(50 \mu \mathrm{M}$ curcumin $)$, and $0.01 \mathrm{ng} / \mathrm{g}(50$ $\mu \mathrm{M}$ curcumin and $10 \mu \mathrm{M}$ dutasteride) (Figure 4).

The combination of curcumin and dutasteride inhibited PSA production. The effects of curcumin, dutasteride and their combination on PSA production were determined by performing an immunoassay on LNCaP cells. Treatment of the cells with $5 \mu \mathrm{M}$ curcumin alone resulted in $58 \%$ inhibition of PSA secretion to the supernatant compared to the control. Treatment of cells with $5 \mu \mathrm{M}$ dutasteride resulted in $48 \%$ inhibition. However, treatment with the combination of $5 \mu \mathrm{M}$ curcumin and $5 \mu \mathrm{M}$ dutasteride resulted in $70 \%$ inhibition of PSA production in LNCaP cells (Figure 5). These results indicated that LNCaP cells treated with curcumin and/or dutasteride produce significantly lower amounts of PSA. Cells that were treated with the combination of $5 \mu \mathrm{M}$ curcumin and $5 \mu \mathrm{M}$ dutasteride showed an even greater decrease in PSA levels (Figure 5).

\section{Discussion}

Testosterone and dihydrotestosterone are critical for the development, maturation, and maintenance of the prostate as well as for carcinogenesis. Blocking testosterone production is a common strategy used to treat metastatic prostate cancer, and successfully reduces the size of local prostate cancer and metastases. High testosterone levels in prostate tissue are linked to a high Gleason score, an advanced clinical stage, and a high percentage of positive biopsy cores in patients with prostate cancer (12). In addition, many studies have shown the involvement of intratumoral steroidogenesis of testosterone and dihydrotestosterone in prostate cancer cells (13). In particular, an increase in de novo testosterone synthesis was shown by an upregulation of enzymes that synthesize testosterone and dihydrotestosterone in castrationresistant prostate cancers which responded well to hormone therapy (13). Although, association between androgen concentrations and prostate cancer occurrence has been challenging to validate in epidemiologic studies (14), there is evidence that intervention in the intraprostatic hormonal environment may reduce the prevalence of some prostate cancers (15). Human aldo-keto reductases (AKRs) are able to convert potent sex hormones into their cognate inactive metabolites and vice versa. In prostate cells, AKR1C2 (3aHSD) acts as a 3-ketosteroid reductase to lower the dihydrotestosterone levels and prevent androgen receptor activation. Curcumin has been shown to induce the expression AKR1C2 in prostate cancer by promoting dihydrotestosterone metabolism (16). On the other hand, dutasteride, a 5-alpha-reductase inhibitor, has been shown to inhibit the conversion of testosterone to dihydrotestosterone (2). In this study, the combination of curcumin and 


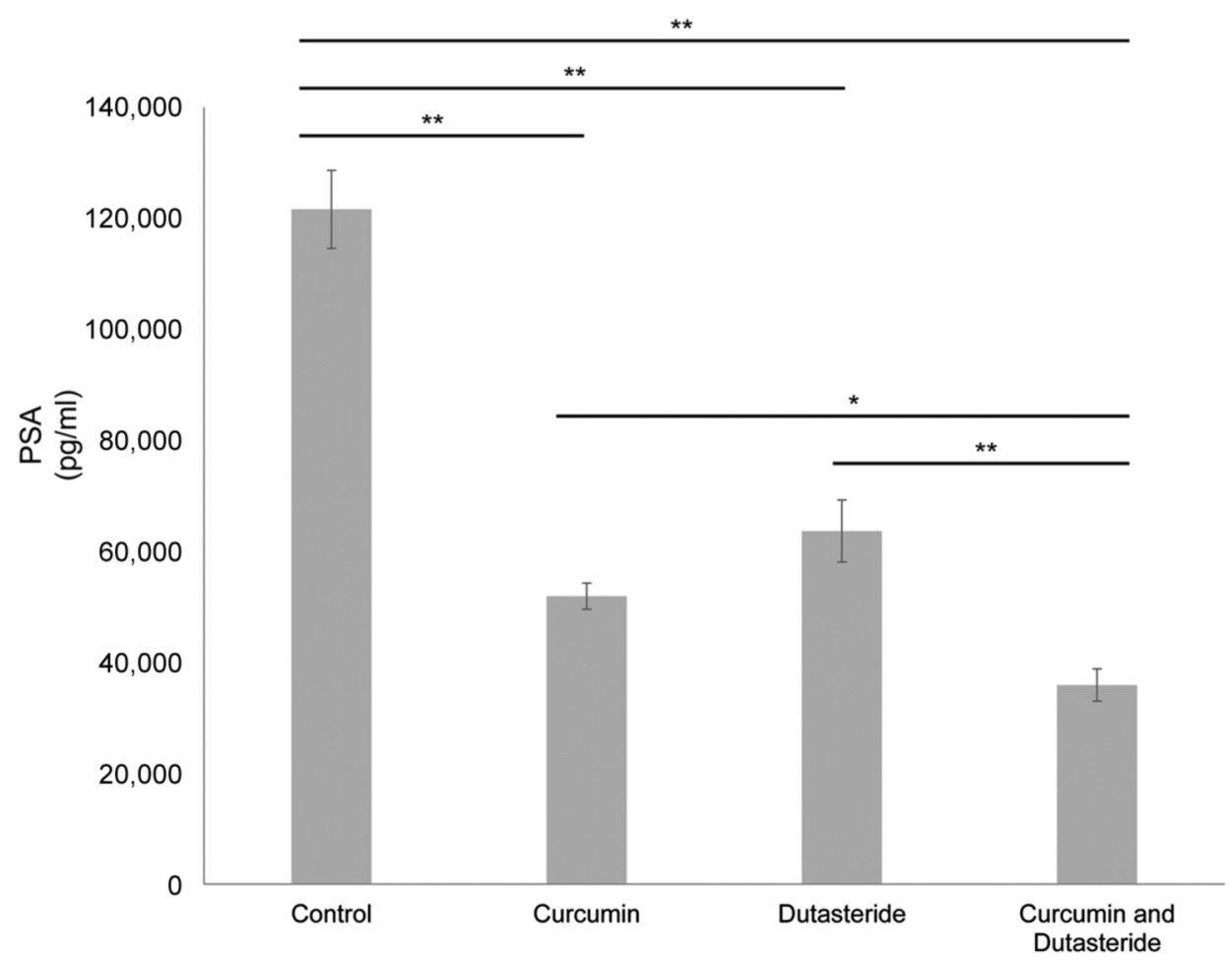

Figure 5. PSA secretion in LNCaP cells after treatment with $5 \mu M$ curcumin and/or $5 \mu M$ dutasteride $(* p<0.05$, $* * p<0.01)$.

dutasteride decreased the intratumoral levels of testosterone and dihydrotestosterone, apoptosis, and PSA production. Although no agreement has yet been reached on the efficacy of suppressing androgen concentrations in prostate cancer tissues for the prevention of prostate cancer, we must consider the impact that androgens and the manipulation of androgen metabolism, have on prostate growth and the intraprostatic hormone environment in men with different stages and pathological grades of the disease.

PSA is an extremely useful tumor marker for prostate cancer screening and treatment decisions, but its remarkable sensitivity introduces the possibility of over-treatment in some cases $(17,18)$. Previously, we administered either supplements containing curcumin as the primary component or a placebo daily for 6 months to 89 patients who had experienced a negative prostate biopsy result. PSA levels were measured at 0,3 , and 6 months. As a result, the experimental group, comprised of subjects with PSA levels measuring $10 \mathrm{ng} / \mathrm{ml}$ or greater, experienced a statistically significant decrease in PSA levels in comparison with to the placebo group $(p<0.001)(19)$. In this study, we demonstrated that the combined effect of curcumin and dutasteride on PSA production reduced intracellular androgen levels. Evidence suggests that the serine protease activity of PSA may be involved in the invasion and metastasis of prostate cancer (20). Mammary serine protease inhibitor (maspin) has been characterized as a tumor suppressor gene and is down-regulated in prostate cancer. Curcumin-mediated maspin induction has been suggested to have therapeutic potential as it has been shown to inhibit the invasion of cancer cells (21). If combined, dutasteride and polyphenols, such as curcumin, could extend the PSA elevation period during postoperative PSA failure, and might present a useful treatment option in terms of patient quality of life (22). A prospective randomised phase III trial is on-going to investigate the effect of curcumin on the recurrence-free survival prostate cancer patients after radical prostatectomy. These various experimental results suggest that, through a variety of action mechanisms, curcumin, dutasteride and their combination have an inhibitory effect on the malignant progression of prostate cancer. Our research team will conduct a clinical investigation to examine whether curcumin and dutasteride have an additional inhibitory effect on PSA and whether they suppress oncogenesis. We will examine whether administration of curcumin and dutasteride could inhibit postoperative rising of PSA levels in subjects who had already received a radical prostatectomy as treatment for localized prostate cancer. Further basic and clinical investigation into the effects of curcumin and dutasteride on androgen signal suppression may produce clinically important results and open new avenues in cancer prevention strategies. 


\section{Disclosure Statement}

The Authors have no conflict of interest.

\section{Conflicts of Interest}

The Authors declare no potential conflicts of interest in relation to this study.

\section{Authors' Contributions}

Hisamitsu Ide: contributed substantially to the study's conception and design, performing experiments, data acquisition and analysis, and writing of the article. Hiroaki Nakayama: contributed substantially to the study's conception and design, performing experiments, data acquisition and analysis, and writing of the manuscript. Yan $\mathrm{Lu}$ and Ayano Takei: contributed substantially to performing experiments and data acquisition and analysis. Akiyoshi Osaka, Gaku Arai and Kazunori Fukuda: contributed substantially to performing experiments and data acquisition and analysis. Hiroshi Okada and Kazutaka Saito: contributed substantially to data interpretation and revision of the article. Shigeo Horie: contributed substantially to the study's conception and design, data interpretation, and revision of the article.

\section{Acknowledgements}

Grant-in-Aid for Scientific Research from The Ministry of Education, Culture, Sports, Science and Technology of Japan.

\section{References}

1 Elshan NGRD, Rettig MB and Jung ME: Molecules targeting the androgen receptor (AR) signaling axis beyond the AR-Ligand binding domain. Med Res Rev 39(3): 910-960, 2019. PMID: 30565725. DOI: $10.1002 /$ med.21548

2 Bartsch G, Rittmaster RS and Klocker H: Dihydrotestosterone and the concept of 5alpha-reductase inhibition in human benign prostatic hyperplasia. World J Urol 19(6): 413-425, 2002. PMID: 12022710. DOI: 10.1007/s00345-002-0248-5

3 Hirshburg JM, Kelsey PA, Therrien CA, Gavino AC and Reichenberg JS: Adverse effects and safety of 5-alpha reductase inhibitors (finasteride, dutasteride): A systematic review. J Clin Aesthet Dermatol 9(7): 56-62, 2016. PMID: 27672412.

4 Andriole GL, Bostwick DG, Brawley OW, Gomella LG, Marberger M, Montorsi F, Pettaway CA, Tammela TL, Teloken C, Tindall DJ, Somerville MC, Wilson TH, Fowler IL, Rittmaster RS and REDUCE Study Group.: Effect of dutasteride on the risk of prostate cancer. N Engl J Med 362(13): 11921202, 2010. PMID: 20357281. DOI: 10.1056/NEJMoa0908127

5 Grubb RL, Andriole GL, Somerville MC, Mahoney C, Manyak MJ and Castro R: The REDUCE Follow-Up Study: low rate of new prostate cancer diagnoses observed during a 2-year, observational, followup study of men who participated in the REDUCE trial. J Urol 189(3): 871-877, 2013. PMID: 23021996. DOI: $10.1016 /$ j.juro.2012.09.099

6 Ide H, Lu Y, Noguchi T, Muto S, Okada H, Kawato S and Horie S: Modulation of AKR1C2 by curcumin decreases testosterone production in prostate cancer. Cancer Sci 109(4): 1230-1238, 2018. PMID: 29369461. DOI: 10.1111/cas.13517
7 Horie S: Chemoprevention of prostate cancer: soy isoflavones and curcumin. Korean J Urol 53(10): 665-672, 2012. PMID: 23136625. DOI: $10.4111 / \mathrm{kju} .2012 .53 .10 .665$

8 Ide H, Yu J, Lu Y, China T, Kumamoto T, Koseki T, Muto S and Horie S: Testosterone augments polyphenol-induced DNA damage response in prostate cancer cell line, LNCaP. Cancer Sci 102(2): 468-471, 2011. PMID: 21134073. DOI: 10.1111/j.13497006.2010.01791.x

9 Sasaki H, Sunagawa Y, Takahashi K, Imaizumi A, Fukuda H, Hashimoto T, Wada H, Katanasaka Y, Kakeya H, Fujita M, Hasegawa $\mathrm{K}$ and Morimoto T: Innovative preparation of curcumin for improved oral bioavailability. Biol Pharm Bull 34(5): 660-665, 2011. PMID: 21532153. DOI: $10.1248 / \mathrm{bpb} .34 .660$

10 Hojo Y, Higo S, Ishii H, Ooishi Y, Mukai H, Murakami G, Kominami T, Kimoto T, Honma S, Poirier D and Kawato S: Comparison between hippocampus-synthesized and circulationderived sex steroids in the hippocampus. Endocrinology 150(11): 5106-5112, 2009. PMID: 19589866. DOI: 10.1210/en.2009-0305

11 Kato A, Hojo Y, Higo S, Komatsuzaki Y, Murakami G, Yoshino $\mathrm{H}$, Uebayashi $\mathrm{M}$ and Kawato S: Female hippocampal estrogens have a significant correlation with cyclic fluctuation of hippocampal spines. Front Neural Circuits 7: 149, 2013. PMID: 24151456. DOI: 10.3389/fncir.2013.00149

12 Miyoshi Y, Uemura H, Umemoto S, Sakamaki K, Morita S, Suzuki K, Shibata Y, Masumori N, Ichikawa T, Mizokami A, Sugimura Y, Nonomura N, Sakai H, Honma S, Harada M and Kubota Y: High testosterone levels in prostate tissue obtained by needle biopsy correlate with poor-prognosis factors in prostate cancer patients. BMC Cancer 14: 717, 2014. PMID: 25256077. DOI: $10.1186 / 1471-2407-14-717$

13 Armandari I, Hamid AR, Verhaegh $G$ and Schalken J: Intratumoral steroidogenesis in castration-resistant prostate cancer: a target for therapy. Prostate Int 2(3): 105-113, 2014. PMID: 25325021. DOI: 10.12954/PI.14063

14 Platz EA and Giovannucci E: The epidemiology of sex steroid hormones and their signaling and metabolic pathways in the etiology of prostate cancer. J Steroid Biochem Mol Biol 92(4): 237253, 2004. PMID: 15663987. DOI: 10.1016/j.jsbmb.2004.10.002

15 Cooper LA and Page ST: Androgens and prostate disease. Asian J Androl 16(2): 248-255, 2014. PMID: 24407178. DOI: 10.4103/1008-682X.122361

16 Ji Q, Chang L, VanDenBerg D, Stanczyk FZ and Stolz A: Selective reduction of AKR1C2 in prostate cancer and its role in DHT metabolism. Prostate 54(4): 275-289, 2003. PMID: 12539226. DOI: $10.1002 /$ pros.10192

17 Bill-Axelson A, Holmberg L, Ruutu M, Häggman M, Andersson SO, Bratell S, Spångberg A, Busch C, Nordling S, Garmo H, Palmgren J, Adami HO, Norlén BJ, Johansson JE and Scandinavian Prostate Cancer Group Study No. 4.: Radical prostatectomy versus watchful waiting in early prostate cancer. N Engl J Med 352(19): 1977-1984, 2005. PMID: 15888698. DOI: 10.1056/NEJMoa043739

18 Welch HG and Albertsen PC: Prostate cancer diagnosis and treatment after the introduction of prostate-specific antigen screening: 1986-2005. J Natl Cancer Inst 101(19): 1325-1329, 2009. PMID: 19720969. DOI: 10.1093/jnci/djp278

19 Ide H, Tokiwa S, Sakamaki K, Nishio K, Isotani S, Muto S, Hama T, Masuda H and Horie S: Combined inhibitory effects of soy isoflavones and curcumin on the production of prostatespecific antigen. Prostate 70(10): 1127-1133, 2010. PMID: 20503397. DOI: $10.1002 / \operatorname{pros} .21147$ 
20 Cumming AP, Hopmans SN, Vukmirović-Popović S and Duivenvoorden WC: PSA affects prostate cancer cell invasion in vitro and induces an osteoblastic phenotype in bone in vivo. Prostate Cancer Prostatic Dis 14(4): 286-294, 2011. PMID: 21826098. DOI: $10.1038 /$ pcan.2011.34

21 Cheng WL, Huang CY, Tai CJ, Chang YJ and Hung CS: Maspin enhances the anticancer activity of curcumin in hormonerefractory prostate cancer cells. Anticancer Res 38(2): 863-870, 2018. PMID: 29374713. DOI: 10.21873/anticanres.12295
22 Mokbel K, Wazir U and Mokbel K: Chemoprevention of Prostate Cancer by Natural Agents: Evidence from molecular and epidemiological studies. Anticancer Res 39(10): 5231-5259, 2019. PMID: 31570421. DOI: 10.21873/anticanres.13720

Received January 5, 2021

Revised February 7, 2021

Accepted February 8, 2021 